\title{
Symmetrical and Antisymmetrical Sequenced Fibers with Epoxy Resin on Rectangular Reinforced Structures under Axial Loading
}

\author{
Authors: Reza Moheimani \\ Reza Sarayloo \\ Hamid Dalir
}

\begin{abstract}
In this study, Finite element Method (FEM) evaluation is performed for the compressive failure of reinforced structures with layered composite shells under axial loading. In addition, embedded delamination between the reinforcing layered composite shells and the core is considered as a defect. The layered composite shells are made of 12 plies of equal thickness of Kevlar, CFC, and E-Glass with epoxy resin. Considering the orientation and laminate, three different layered composite shells, $\left(0^{\circ} / 90^{\circ} / 0^{\circ} / 90^{\circ} / 0^{\circ} / 90^{\circ}\right),\left(45^{\circ} /-45^{\circ} / 0^{\circ} / 90^{\circ} / 60^{\circ} /-30^{\circ}\right)$, and $\left(60^{\circ} /-30^{\circ} / 90^{\circ} / 0^{\circ} / 30^{\circ} / 90^{\circ}\right)$, are considered for symmetrical and antisymmetrical sequences. These results are obtained through ABAQUS simulations and subsequent analysis. The results show that symmetrical and antisymmetrical sequences can be used as an index for quality control and as a safety factor of composite shells produced by the hand lay-up technique in certain industrial processes. The delamination growth is also investigated with the help of cohesive elements. Buckling phenomenon occurred abruptly due to the fast propagation of delamination, having face/core debond.
\end{abstract}

\section{Keywords}

Delamination of Layer, Sequence of Layered Composite, Compressive Loading, Fracture Mechanics, Finite Element.

\section{INTRODUCTION}

The ever-increasing demand for lightweight and efficient structures has led engineers and scientists to use composite materials in several applications. The design of composite materials is aimed at achieving superior performance with unique thermomechanical properties and specific strengths, which cannot be achieved using traditional materials.

In particular, layered polymeric composites have many potential applications in a variety of engineering fields. However, composite materials possess strong in-plane material properties, though they usually lack strength in the direction normal to fiber orientation [1]. This is attributed to their laminated forms with relatively weak interlaminar interfaces, exhibiting low resistance against shear

Reza Moheimani, Reza Sarayloo, Hamid Dalir, Department of Mechanical and Energy Engineering, Purdue School of Engineering and Technology, IUPUI, IN, USA. 
and compression. As a consequence, interlaminar cracks, for example, delamination at the interface between two layers, can be initiated. This phenomenon is termed delamination, and it is one of the most common modes of failure in composite structures. Delaminations will significantly reduce the load-carrying capacity and stability of components [2]. Many experimental and numerical results related to the ultimate strength of debonded shells have been published, for example, the studies of Sørensen et al. [3,4], Branner and Berring [5], and Benloulo and Sanchez [6]. Modeling of composites failure behavior has become the main objective in studies over the years, as seen in the studies of Gaiotti et al. [7], Short et al. [8], Li et al. [9], and Wright [11]. Delamination is particularly important in sandwich structures under compressive loading because the loss of stiffness leads to failure by buckling [12].

\section{BASIC CONCEPT}

Manufacturing defects, bird strike, impact of runway debris, and tool drops are some of the causes of delamination. Delamination due to transverse shear and normal stresses is a complex phenomenon, and hence, predicting these interlaminar stresses is difficult [13]. At present, higher fiber contents have been made possible by innovative fabrication processes, such as vacuum infusion, recently introduced in the marine industry. Therefore, it is now possible to fabricate increasingly thinner layers with sufficient strength for the intended structural applications. In the case of sandwich structures, the thickness of shells is much less than in single-layered shells [14]. Many studies have developed into failure by buckling; these include the studies of Aslan and Shahin [15], Wang and Abdalla [16], Ji and Waas [17], Moradi and Taheri [18], Safaei and Fattahi [19-20], Hosseini et al. [21], and Liu and Zheng [22].

The previous studies have brought attention to the fact that applied loads and behavior of structures lead to failure by increased delamination. Moreover, owing to the difficulty in detecting delamination, it is usually the most critical type of damage that composite and sandwich structures experience under compressive loads [23]. Delamination was analytically modeled by applying the well-established sandwich theory in earlier times, and this method is still employed in the preliminary design as quick estimates [24].

For reinforced composite structures, one must consider the bending strength of the layered composite shells and the shear strength of the core separately. In other words, the interactions between the shells and the core are being neglected. Composite shell elements, whose stiffness matrix is based on the classical laminate theory formulation, are successfully used as finite elements. Hence, the core is simulated as one of the laminate shells when the overall laminate bending behavior is of interest and imperfections such as delaminations are not explicitly considered. The use of shell elements for analyzing the behavior of composite shells via FEM has been extended. Generally, reinforced structures are simulated by applying different strategies depending on the specific goal of the analysis [25]. Composite shell elements, whose stiffness matrix is based on the classical laminate theory formulation and size of meshed elements, depend on the layered composite shell thickness considered in the analysis. Therefore, meshed elements are used in finite element simulation analysis for nodeto-node coupling between the layered composite shell elements and the core.

There is a mismatch between the suitable element size necessary to model the layered composite shells and the core because the classical sandwich theory, which is the theoretical basis of the definition of layered composite shell elements, reduces the essentially three-dimensional composite to a two-dimensional, deformable reference surface with appropriate bending and shear stiffness properties. On the other hand, the computation costs of three-dimensional modeling are impractical for regular engineering purposes [26]. In fact, the assumption of neglecting the actual shear stress distribution in the thickness may lead to overestimation of the bending stiffness because of the 
relatively larger dimension of the PVC core with respect to the shells. Because brick elements simulate three-dimensional strain fields well, they should be used when the thickness is not negligible with respect to the other dimensions. On the other hand, when problems arise owing to bending stresses, a brick model needs several through-thickness elements to properly reproduce the bending effects.

However, when the shell is very thin, a large number of elements are needed to achieve reliable computation to prevent problems due to the relatively high aspect ratios and high possibility of distortion of the elements. This eventually results in very high computation costs of the numerical model.

One problem arising from the use of very thin shell elements is the well-known phenomenon of shear locking: element locking has been widely discussed [27]. It is the phenomenon of an element being too stiff as compared to reality. In essence, the phenomenon arises because the interpolation functions used to map strains and stresses in the elements cannot represent zero (or very small) shear or membrane strains. If the element cannot represent zero shear strains, and the physical situation corresponds to zero (or very small) shear strains, then the element becomes very stiff as its thicknessto-length ratio decreases. If a sandwich structure is under compressive loading, and a plate or beam is bent, the maximum stresses occur at the top and bottom surfaces. Therefore, it makes sense to use high-strength materials only at the top and bottom and low-strength and lightweight materials in the middle.

The strong and stiff facings also support axial forces. In addition, the resistance to bending of a rectangular cross-sectional beam/plate is proportional to the cube of the thickness. Thus, increasing the thickness by adding a core in the middle increases this resistance. Note that the highest shear forces occur in the middle of the sandwich structure, and thus, the core is necessary for supporting the shear [28].

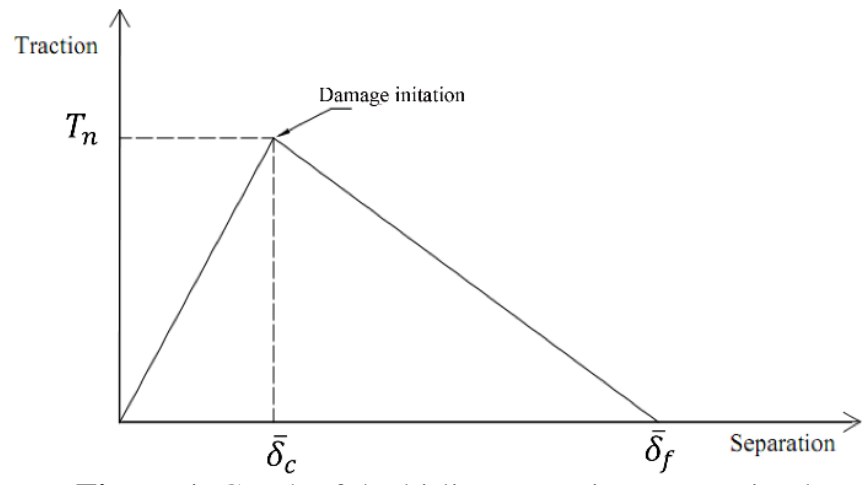

Figure 1. Graph of the bi-linear traction- separation law

Focusing on delaminations, the cohesive zone model (CZM), implemented in FE codes through suitable elements (cohesive elements), is one of the most used approach to simulate the onset and the propagation of delaminations in composite structures [25-28]. As mentioned earlier, composite delamination is one of common defect that occurs on sandwich structures reinforced by composite laminates. Current studies have investigated the effect of layer delamination growth on compressive strength of composite structures. To effectively model damage evolution within a material or structure with bonded components, cohesive zone models (CZM's) coupled to conventional FE analyses was used the most widespread method of predicting static or fatigue damage uptake in structures [3-5].

Focusing on delaminations, the cohesive zone model (CZM), implemented in FE codes through suitable elements (cohesive elements), is one of the most used approach to simulate the onset and the propagation of delaminations in composite structures [25-28].CZM's are based on the concepts of stress and fracture mechanics and can be fitted into the local or continuum approach, since they can either be considered to model the interfacial fracture behaviour of equally or differently oriented plies in stacked composites, (fig. 1). The CZM laws are established between paired nodes of cohesive 
elements, and they can be used to connect superimposed nodes of elements representing different materials or different plies in composite. Cohesive elements captured the crack initiation as well as the process of crack propagation. Effect of delamination growth on buckling response of sandwich was investigated using cohesive elements (COH3D8)

\section{MODELING OF STRUCTURE}

There are three analyses in simulations, first analysis is for sandwich structures without delamination which is a perfect structure. Second analysis is done for sandwich structures without delamination growth, turn in third analysis is for sandwich structures with growth of delamination with cohesive elements. Delamination is between core and composite laminates $50 \mathrm{~mm}$ length. While buckling phenomenon occurs, delamination is suddenly propagated The results of FEM output indicate that effect of delamination length is considerable on buckling load. Delamination and its growth likely resulted in dropping of buckling load. Delamination growth has been investigated by cohesive elements with defect code and compare with experience results on buckling load in sandwich structures.

As we mentioned earlier, the dimension of sandwich structure is given in Table 1, addressing the area of delamination. The cores are made of PVC (Polyvinyl Chloride) and from H45 and H80 that is named cores is based on the numerical value of the density of each of them [29].

Results were compared with those of a previous study [30] for verification. For further studies, research was conducted to determine the buckling behavior of reinforced sandwich structures with composite shells for symmetrical and antisymmetrical sequences. Two cores were tested with different elastic moduli, and both cases were considered in order to evaluate the effect of core stiffness on the numerical simulation. Table 2 lists the mechanical properties of each core, as reported in industrial experiments. Table 3 reports the mechanical properties of each of the reinforcing layered composite shells.

\begin{tabular}{|c|c|c|c|}
\hline Area & $\begin{array}{l}\text { Length } \\
\text { (mm) }\end{array}$ & Area & Length (mm) \\
\hline 38 & $\mathrm{~d}$ & 100 & $\mathrm{a}$ \\
\hline 50 & $\mathrm{~L}$ & 50 & b \\
\hline
\end{tabular}

Table 2 MECHANICAL PROPERTIES OF CORE

\begin{tabular}{lccc}
{$[29,30]$} & & & \\
\hline Core & E (Mpa) & $\mathrm{G}(\mathrm{Mpa})$ & $\rho\left(\mathrm{kg} / \mathrm{m}^{3}\right)$ \\
\hline H45 & 42 & 18 & 45 \\
H80 & 80 & 30 & 80 \\
\hline
\end{tabular}

Table 3 MECHANICAL PROPERTIES OF COMPOSITE SHELL [65, 66]

\begin{tabular}{cccc}
\hline Properties & \multicolumn{3}{c}{ Material } \\
\hline & Kevlar & CFC & E-Glass \\
\cline { 2 - 4 }$X_{G}(\mathrm{Mpa})$ & 250 & 120 & 70 \\
$\rho\left(\mathrm{kg} / \mathrm{m}^{3}\right)$ & 1400 & 1800 & 1900 \\
$X_{C}^{L}(\mathrm{Mpa})$ & 500 & 111 & 690 \\
$X_{T}^{L}(\mathrm{Mpa})$ & 3100 & 2724 & 1050 \\
$X_{C}^{T}(\mathrm{Mpa})$ & 1800 & 1690 & 140 \\
$X_{T}^{T}(\mathrm{Mpa})$ & 150 & 50 & 55 \\
$E_{L}(\mathrm{Gpa})$ & 195 & 164 & 38 \\
$E_{T}(\mathrm{Gpa})$ & 14.6 & 12.8 & 8.27 \\
$G_{12}(\mathrm{Gpa})$ & 7.5 & 4.5 & 4.14 \\
$G_{23}(\mathrm{Gpa})$ & 5 & 2.5 & 4 \\
$\mu_{12}$ & 0.3 & 0.32 & 0.25 \\
$\mu_{23}$ & 0.45 & 0.45 & 0.27 \\
\hline
\end{tabular}




\section{PERFECT STRUCTURE VS STRUCTURE WITH DELAMINATION VS STRUCTURE WITH DELAMINATION GROWTH}

An analytical function is used to simulate a thick core with soft behavior. It is modeled separately in the analysis. Such a function can explain the effects of transverse stiffness of the core. It is clear that there are complexities in the simulation of the behavior of reinforced structures under compressive loading. Therefore, the reinforcing layered composite shells and the core exhibit different structural behaviors when coupled. If delaminations are present, such coupling is further discontinuous in the whole sandwich structure.

Where there is no separation between the reinforcing layered composite shells and the core, the shells and the core are connected by node-to-node connection, but where there is a separation, reinforcing layered composite shell elements and the core are connected via surface contacts and reactions. If delaminations exist between the reinforcing layered composite shells and the core, they are an extremely critical aspect of the structure. Generally, buckling in structures under compressive loading is unavoidable. Global buckling is the instability of the whole section of the sandwich structure, which maintains its shape and shifts globally out of plane owing to compressive loading, while local buckling is considered as the buckling of a portion of the cross section of the layered composite shell [31].

For further studies, research was conducted to determine the buckling behavior of reinforced sandwich structures with composite shells for symmetrical and antisymmetrical sequences. Fig. 2 shows geometry of modeling for reinforced perfect structure. Secondary, the structure with an implemented separation/debonding is being investigated. This separation is just embedded in one side of composite face/shell between core and composite layers as shown in fig. 3 .

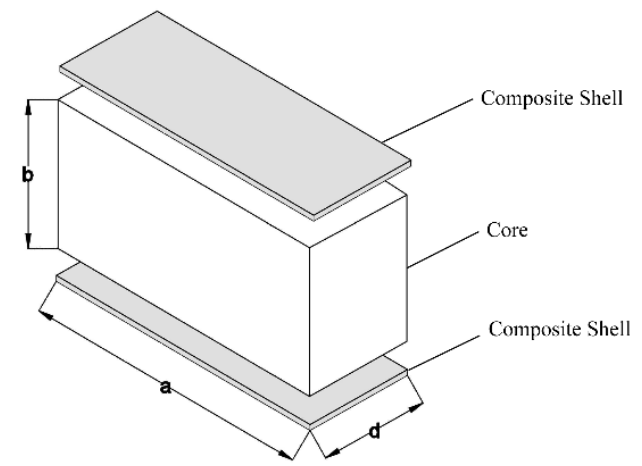

Figure 2. Geometry of modeling for reinforceed perfect structure

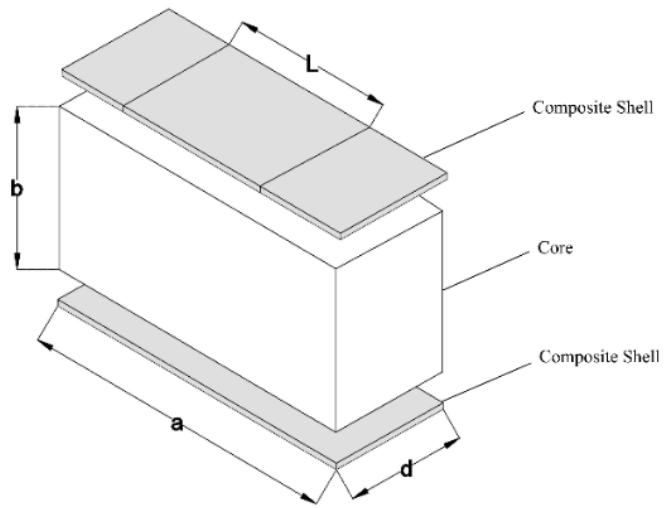

Figure 3. geometry modeling for reinforceed structure with embedded delamination

After all, presented cohesive element allows the simulation of delamination failure in bonded joints on a full scale structural level. Utilizing of cohesive element enables us to simulate more precisely sandwich structures while they are under axial load. This type of elements acts like a glue 
with specific mechanical properties, as the separation tends to propagate. The schematic of the structure with embedded separation is demonstrated in fig 4. Reinforcing layered composite shells are separately connected to each side of the core, with one side having a strong connection without debonding and the other side has no specific debonding.

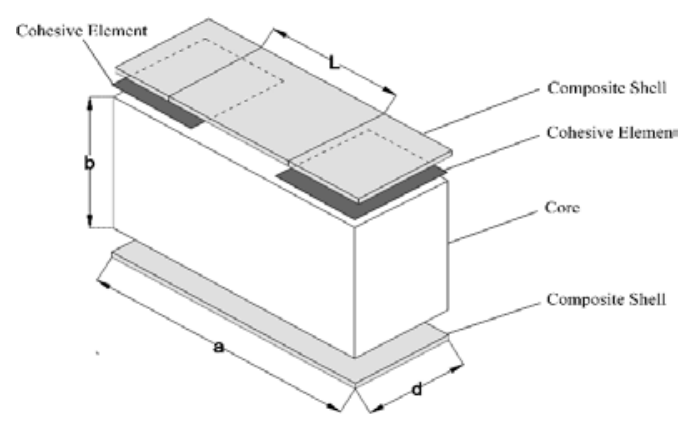

Figure 4. geometry modeling for reinforceed structure with embedded delamination and cohesive element

Reinforcing layered composite shells are made of Kevlar/Epoxy, CFC/Epoxy and E-Glass/Epoxy. Table. 3, reports stiffness and strength properties in longitudinal and transversal directions as well as tensile, shear and compressive strength. Reinforcing layered composite shells separately are connected in two cores $\mathrm{H} 45$ and H80, whereas on one side of the core, shells having quite firmly and without separation and the other side, core has a separation between the shell and core.

Fig. 5, Attention to boundary conditions, applied displacement on the reinforced structure with layered composite shells in perpendicular degrees of freedom and DoF in whole orientation are limited and can be estimate applied loads. Also, in bottom of structure used coupling that whole of DoF are limited. Fig. 6, indicate orientation and laminate in reinforcing layered composite shells for symmetrical and asymmetrical sequence. In finite element is very important considering to how to connect the reinforcing layered composite shells to three-dimensional elements of the core. Layers/Laminate in reinforcing composite shells containing to 12 ply. There is six difference such as $\left[0^{\circ} / 90^{\circ} / 0^{\circ} / 90^{\circ} / 0^{\circ} / 90^{\circ}\right],\left[45^{\circ} /-45^{\circ} / 0^{\circ} / 90^{\circ} / 60^{\circ} /-30^{\circ}\right]$ and $\left[60^{\circ} /-30^{\circ} / 90^{\circ} / 0^{\circ} / 30^{\circ} / 90^{\circ}\right]$ and with separately and for symmetrical and antisymmetrical sequnce, are to be used in the present study, Fig. 7 and 8 . Reinforcing shells from layered shell elements and core from solid elements that is known by surface contact between the reinforcing layered composite shells and the core.

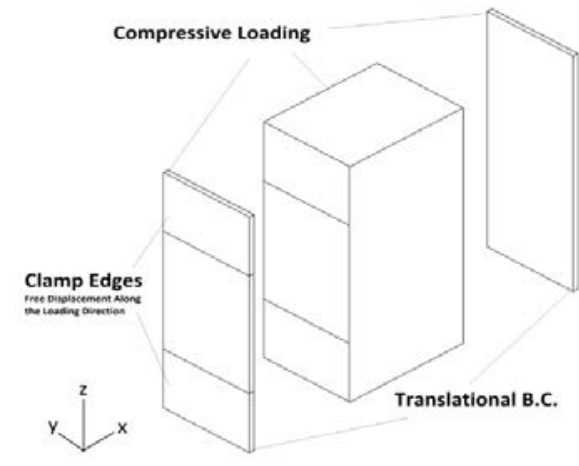

Figure 5. Boundary Condition of Structure 
a) Symmetrical Sequence

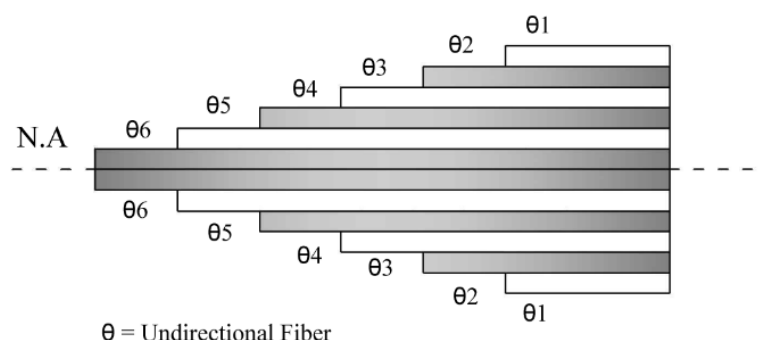

b) Anti-Symmetrical Sequence

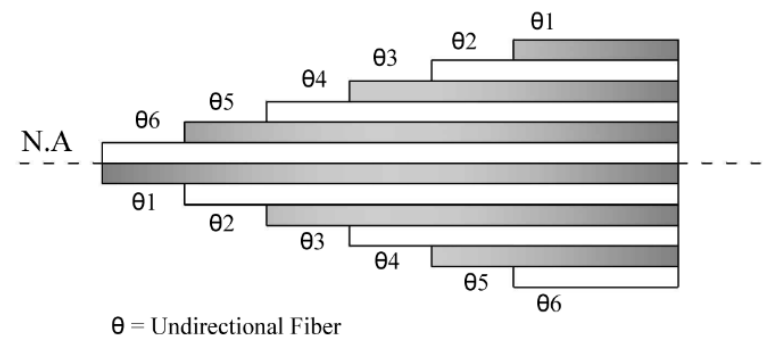

Figure 6. Schematic of Symmetrical and Anti-symmetrical sequence in layered composite shells

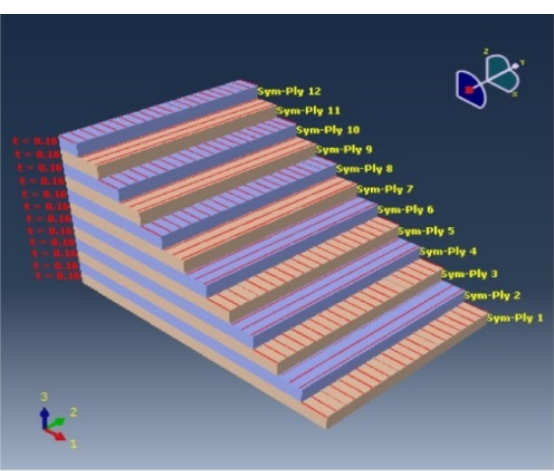

(a)

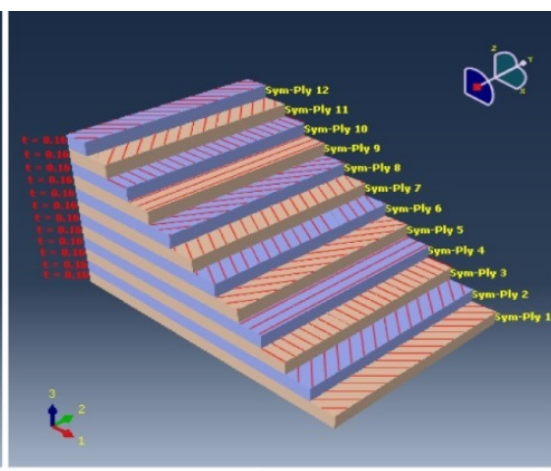

(b)

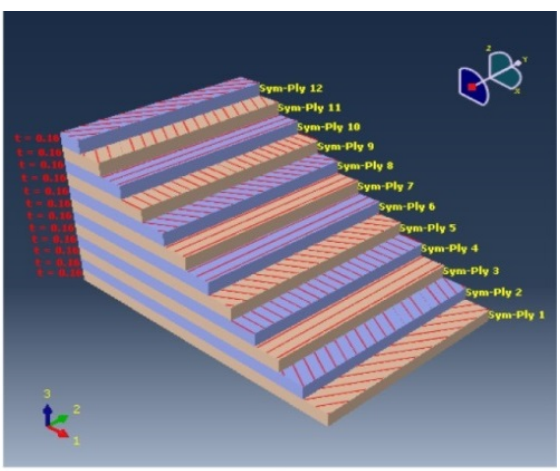

(c)

Figure 7. Symmetric sequence a) $\left[0^{\circ} / 90^{\circ} / 0^{\circ} / 90^{\circ} / 0^{\circ} / 90^{\circ}\right] \quad$ b) $\left[45^{\circ} /-45^{\circ} / 0^{\circ} / 90^{\circ} / 60^{\circ} /-30^{\circ}\right]$

c) $\left[60 \%-30 \% / 90^{\circ} / 0^{\circ} / 30^{\circ} / 90^{\circ}\right]$

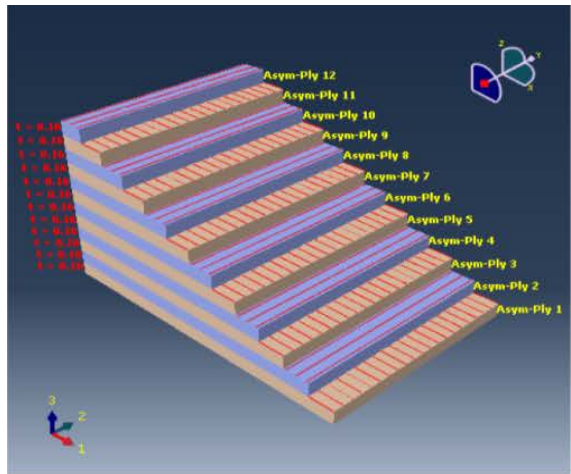

(a)

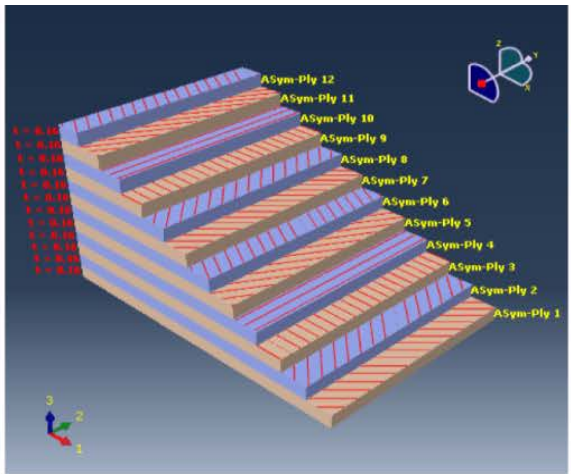

(b)

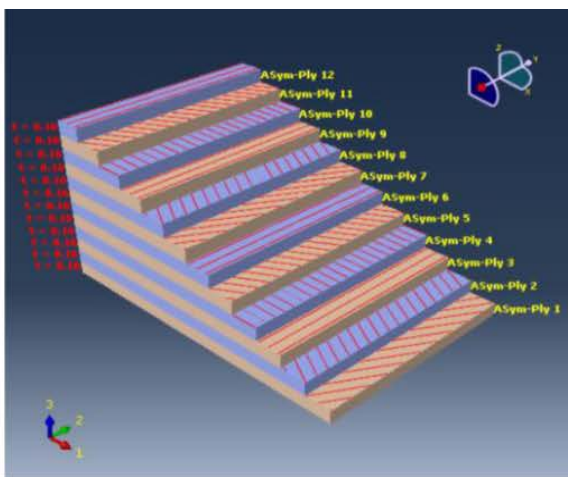

(c)

Figure 8. Anti-symmetric sequence a) $\left[0^{\circ} / 90^{\circ} / 0^{\circ} / 90^{\circ} / 0^{\circ} / 90^{\circ}\right]$ b) $\left[45^{\circ} /-45^{\circ} / 0^{\circ} / 90^{\circ} / 60^{\circ} /-30^{\circ}\right]$

c) $\left[60^{\circ} /-30^{\circ} / 90^{\circ} / 0^{\circ} / 30^{\circ} / 90^{\circ}\right]$.

\section{CLASSICAL LAMINATION THEORY}

If the lamina is thin and does not carry any out-of-plane loads, one can assume plane stress conditions for the lamina. Gaiotti [1] primarily calculated the governing equation of stress and strain tensors. Matrices $[\mathrm{N}]$ and $[\mathrm{M}]$ are the total force and moment resultants equal to the respective sums of their mechanical components, which is generally expressed as in Eq. (1):

$$
\left[\frac{N}{M}\right]=\left[\frac{A}{B} \mid \frac{B}{D}\right]\left[\frac{\varepsilon^{0}}{\kappa}\right]
$$


Matrices [A], [B], and [D] relate the force and bending to strain and curvature of the middle plane, as shown in Eq. 2. The extensional stiffness matrix [A] relates the resultant in-plane forces to the inplane strains, and the bending stiffness matrix [D] relates the resultant bending moments to the plate curvature. The coupling stiffness matrix [B] couples the force and moment terms to the midplane strain and midplane curvature.

$$
\begin{gathered}
A_{i j}=\sum_{k=1}^{n}\left[\left(\bar{E}_{i j}\right)\right]_{k}\left(h_{k}-h_{k-1}\right) \\
B_{i j}=\frac{1}{2} \sum_{k=1}^{n}\left[\left(\bar{E}_{i j}\right)\right]_{k}\left(h_{k}^{2}-h_{k-1}^{2}\right) \\
D_{i j}=\frac{1}{3} \sum_{k=1}^{n}\left[\left(\bar{E}_{i j}\right)\right]_{k}\left(h_{k}^{3}-h_{k-1}^{3}\right)
\end{gathered}
$$

Where $\left[\left(\overline{\boldsymbol{E}}_{\boldsymbol{i j}}\right)\right]_{\boldsymbol{k}}$ are the elastic moduli of k-th ply in i and j directions and $\boldsymbol{h}_{\boldsymbol{k}}$ are the distances from the neutral axis of the k-th ply.

\section{FINITE ELEMENT METHOD RESULTS}

In previous studies, the emphasis was on the prediction of buckling behavior of reinforced structures with layered composite shells. Composite shells are made of glass and vinylester and connected to the core of $\mathrm{H} 45$ and H80, and the reinforcing shells and cores are separated. The loaddisplacement curves obtained via the present simulations are shown in Fig. 9 and compared to the results of a simulation performed in a previous study [31]. Reinforcing layered composite Shells are made of Kevlar/Epoxy, CFC/Epoxy and E-Glass/Epoxy. Fig. 10, shows schematics are obtained from

the finite element analysis for the deformation of structure with reinforcing shells under loading (no delamination growth). It is descriptive of buckling structure in a perfect structure and a structure with delamination

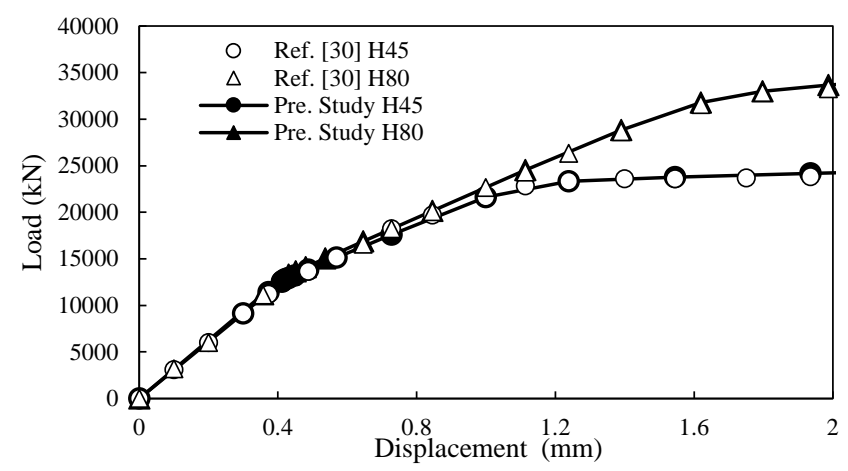

Figure 9. Load-displacement curve in present study and reference [31]

The cohesive zone must be discretized with a single layer of cohesive elements through the thickness. If the cohesive zone represents an adhesive material with a finite thickness, the continuum macroscopic properties of this material can be used directly for modeling the constitutive response of the cohesive zone. Alternatively, if the cohesive zone represents an infinitesimally thin layer of adhesive at a bonded interface, it may be more relevant to define the response of the interface directly in terms of the traction at the interface versus the relative motion across the interface. FE model of each structure is developed using the material properties of cohesive elements that are provided in Table 4. All specimens are unidirectional and the fibers are aligned with the direction of fracture propagation. To demonstrate delamination growth in the structure, the cohesive zone model is an 
appropriate selection. Therefore, the core element (C3D8R) used in FE software is able to calculate shear and normal stresses, precisely. To model of composite layers, (S8R) is employed and finally in order to simulate and predict the separation growth, cohesive elements (COH3D8) has been used. Thus, cohesive elements are implemented to show buckling of structure with delamination growth under axial loading, Fig 11. The effects of separation, orientation, and laminate fibers with symmetric and antisymmetric sequences on the buckling behavior of reinforced structures with composite shells under axial loading were also studied.

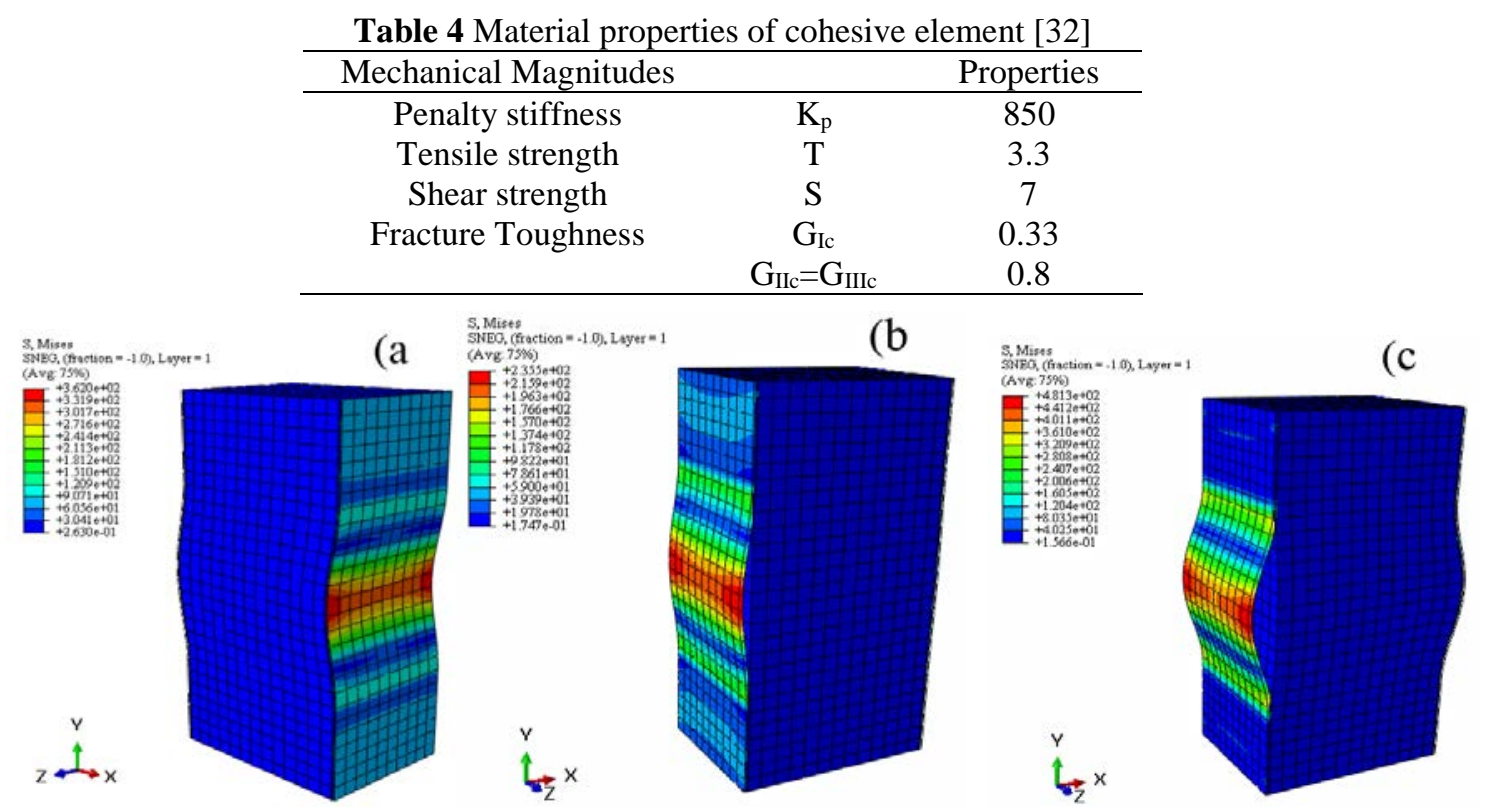

Figure 10. a) Global Buckling for Perfect structure, b) Local Buckling and C) Global Buckling for structure with embedded delamination
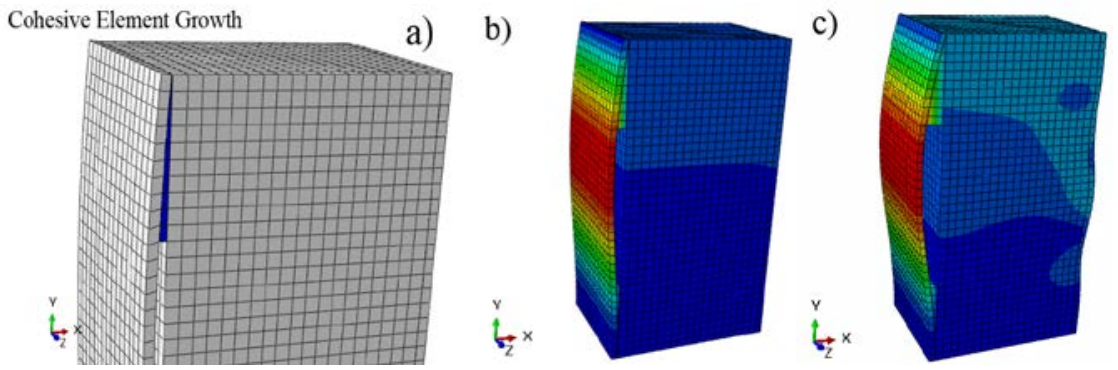

Figure 11. a) separation of cohesive elementin structure with delamination, b) Local and c) Global Buckling for structure with delamination growth

Although, most reinforcing layered composite shells in use are today symmetrical, but can to access to achieve design to specific and complex structures use to anti-symmetrical layered composites in occasionally. Similarly, it investigated to check the applied load in symmetrical and anti-symmetrical composite shells for structure with delamination and delamination growth. Fig. 12a displays a reinforced structure with Kevlar/epoxy-layered composite shells, and it shows the effect of delamination for symmetric and antisymmetric sequences. Also, in Fig.12-b, a reinforced structure with Kevlar/Epoxy shell with delamination growth has been investigated for different sequences. It is clear that how the delamination growth plays significant role in decreasing compressive loading. With regard to the properties and mechanical behavior of reinforcing shells, the numerical analysis 
indicates that local buckling force in the first slope is linear and obtained at an early stage, and when layered composite shells start failing, the slope magnitude is suddenly lowering till global buckling occurs and eventually the whole structure fails.

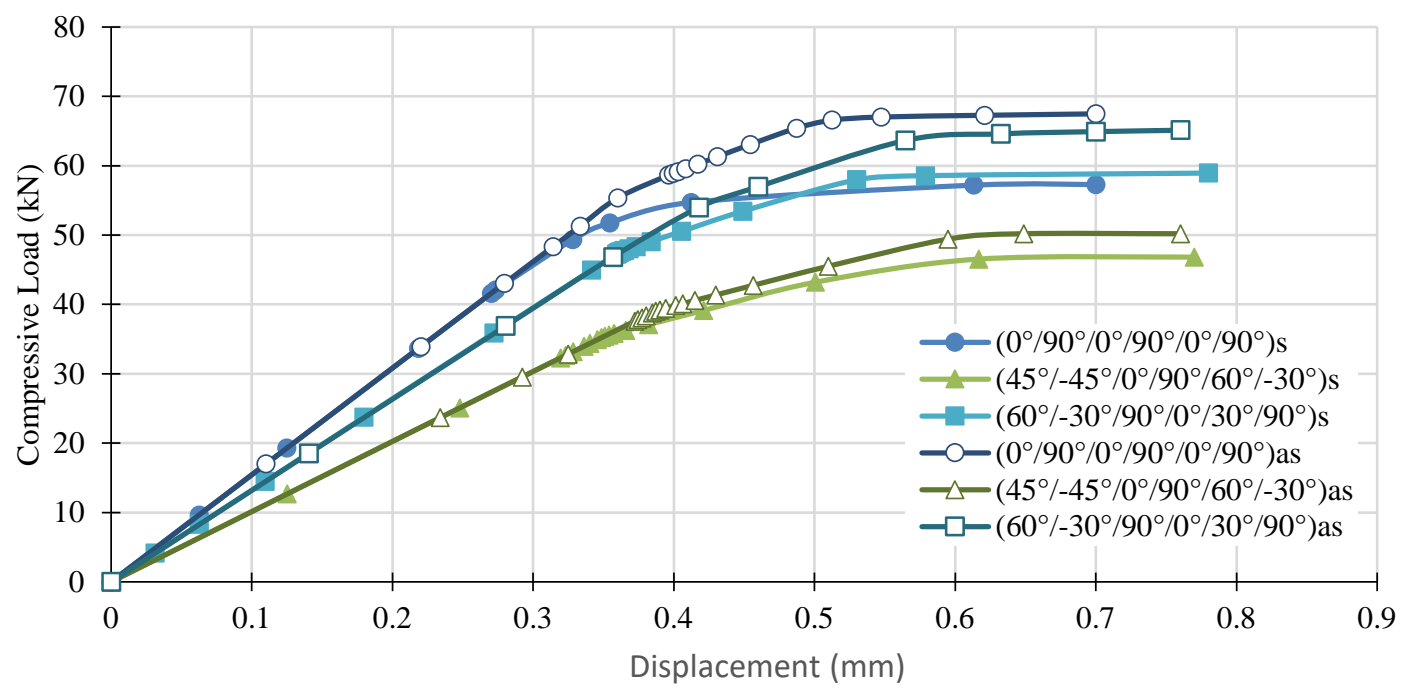

a)

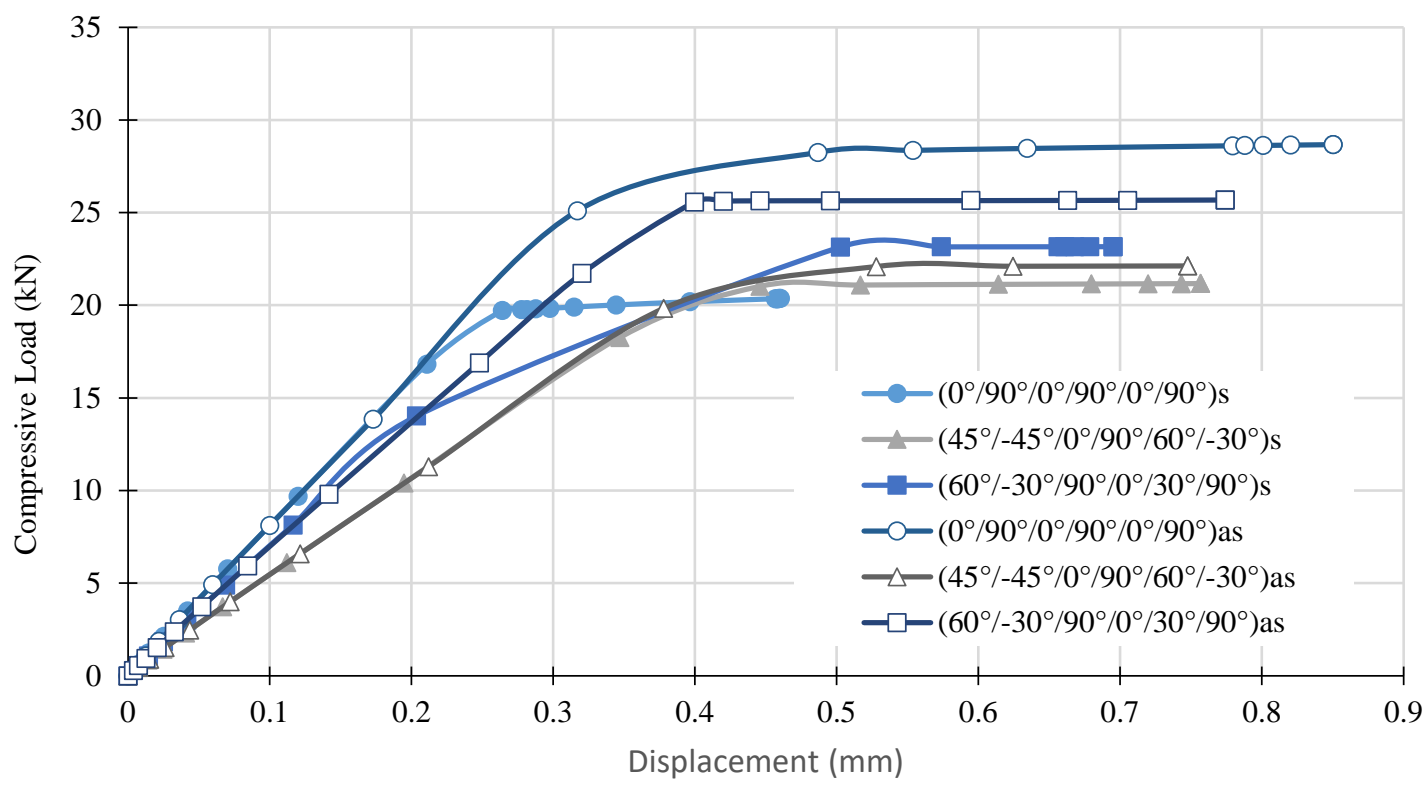

b)

Figure 12. Applied compressive load on structure with Kevlar/Epoxy and H45 core for Symmetrical and Antisymmetrical sequence - a) With Delamination b) With Delamination Growth

\section{LOCAL AND GLOBAL BUCKLING FOR STRUCTURES WITH EMBEDED DELAMINATION AND DELAMINATION GROWTH}

Fig. 13-15 show the effects of separation and laminate fibers in symmetrical and antisymmetrical sequences in another structure with different layered composite shells and the core. Although most reinforcing layered composite shells in use today are symmetrical, antisymmetrical layered composites are occasionally used to design specific complex structures. Similarly, in all specimens, 
simulation was performed for layered composite shells for symmetrical and antisymmetrical sequence with the H45 and H80 cores.

Aslan and Shahin [15] studied the compressive failure of layered composite shells with large delamination. They used different layered composite shells with symmetrical and antisymmetrical sequences. According to Fig. 13, the results show that the bending strength of structures with CFC/epoxy in the antisymmetrical sequence is much greater than that of structures with symmetrical sequence in three different layered composite shells $\left(0^{\circ} / 90^{\circ} / 0^{\circ} / 90^{\circ} / 0^{\circ} / 90^{\circ}\right)$, $\left(45^{\circ} /-45^{\circ} / 0^{\circ} / 90^{\circ} / 60^{\circ}\right.$ $\left.30^{\circ}\right)$, and $\left(60^{\circ} /-30^{\circ} / 90^{\circ} / 0^{\circ} / 30^{\circ} / 90^{\circ}\right)$. As shown in Fig. 14, the bending strength of structures with Eglass/epoxy with $\mathrm{H} 45$ core with the symmetrical sequence in $\left(0^{\circ} / 90^{\circ} / 0^{\circ} / 90^{\circ} / 0^{\circ} / 90^{\circ}\right)$ and $\left(45^{\circ}\right.$ $\left.45^{\circ} / 0^{\circ} / 90^{\circ} / 60^{\circ} /-30^{\circ}\right)$ is much greater than that with antisymmetrical sequence. Note that for $\left(60^{\circ} /-\right.$ $\left.30^{\circ} / 90^{\circ} / 0^{\circ} / 30^{\circ} / 90^{\circ}\right)$, the antisymmetrical sequence bending strength is greater than that with symmetrical sequence.
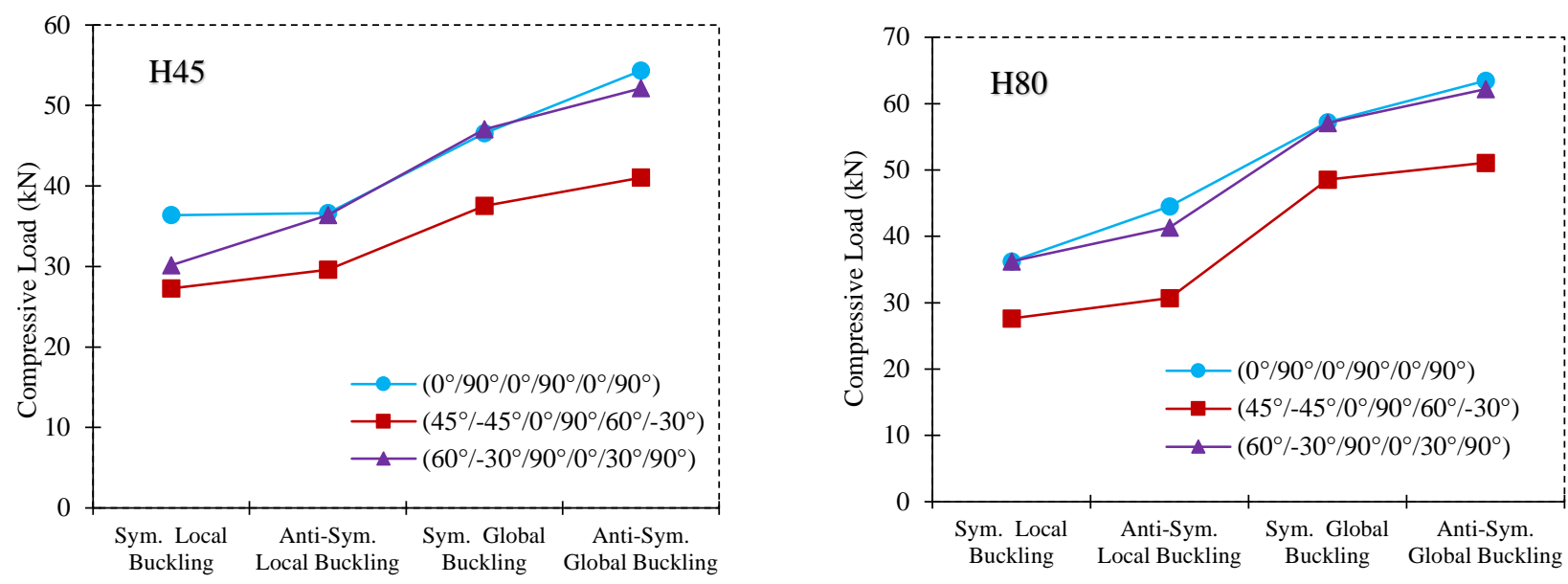

Figure 13. Compressive load of structure with delamination for H45, H80 cores and CFC/Epoxy shells
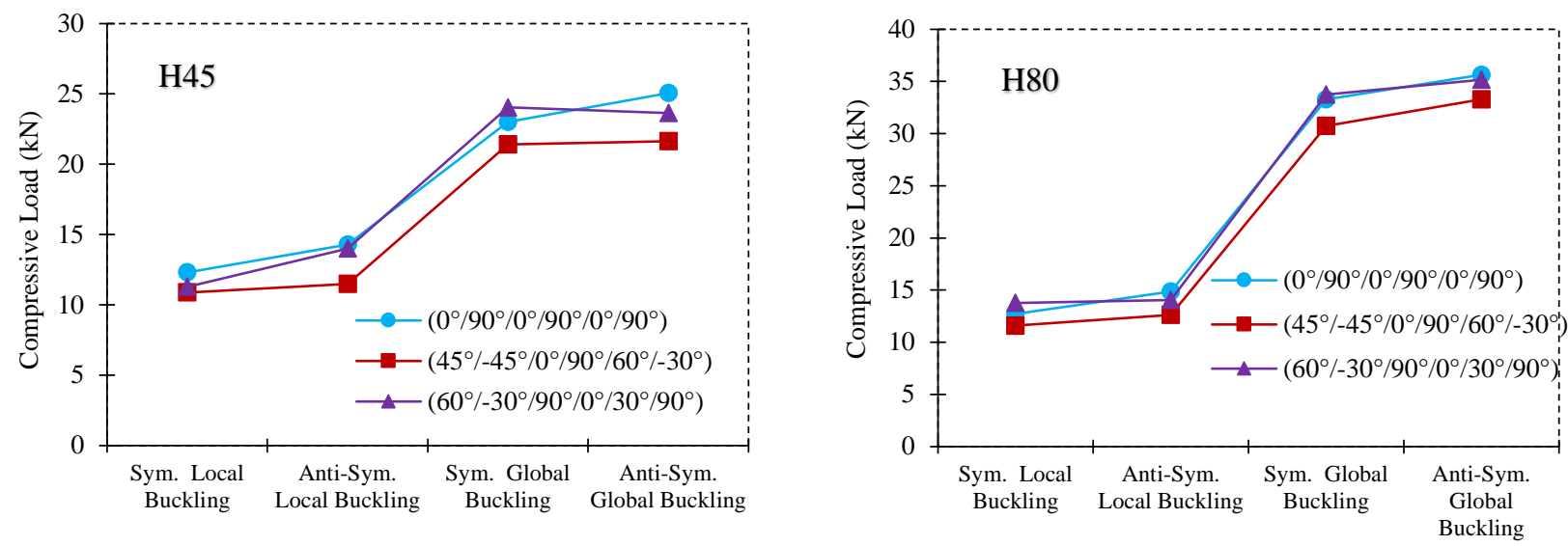

Figure 14. Compressive load of structure with delamination for H45, H80 cores and E-Glass/ Epoxy shells 

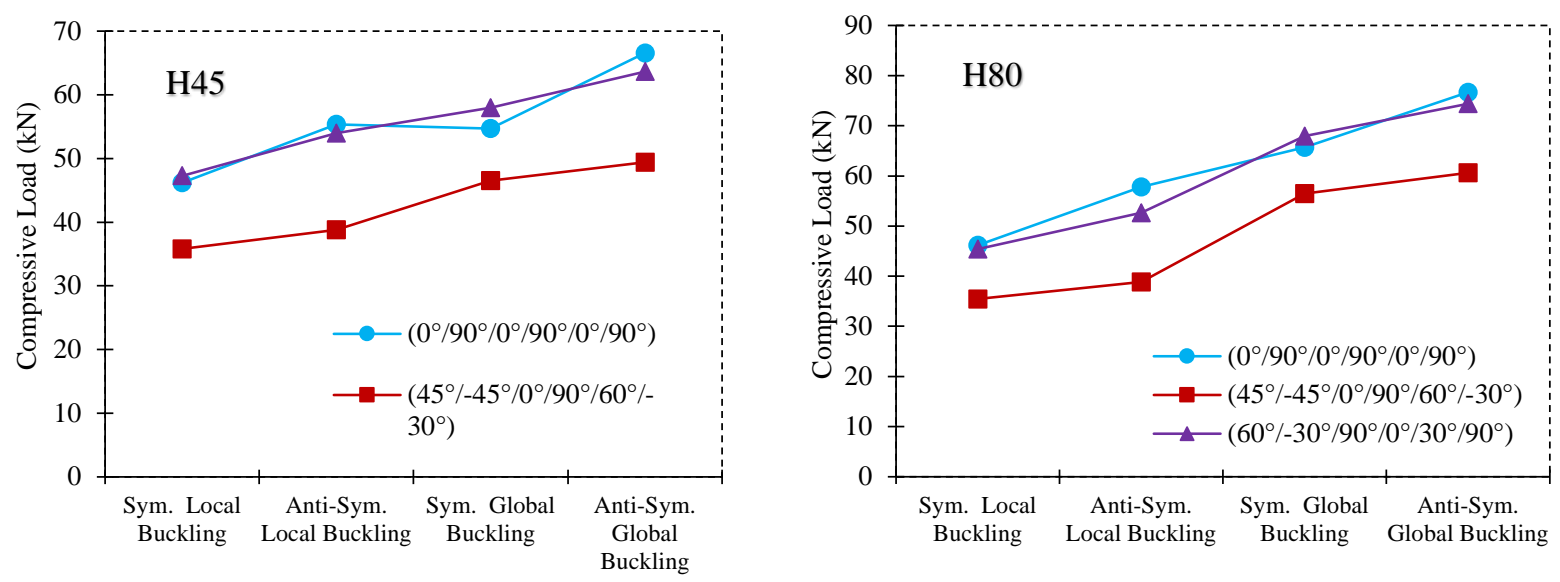

Figure 15. Compressive load of structure with delamination for H45,H80 cores and Kevlar/Epoxy shells

For E-glass/epoxy with H80 core with $\left(45^{\circ} /-45^{\circ} / 0^{\circ} / 90^{\circ} / 60^{\circ} / 30^{\circ}\right)$ and $\left(60^{\circ} / 30^{\circ} / 90^{\circ} / 0^{\circ} / 30^{\circ} / 90^{\circ}\right)$, the antisymmetrical sequence is stronger than the symmetrical one. In structures with Kevlar/epoxy with $\mathrm{H} 45$ core $\left(0^{\circ} / 90^{\circ} / 0^{\circ} / 90^{\circ} / 0^{\circ} / 90^{\circ}\right)$ and $\left(60^{\circ} /-30^{\circ} / 90^{\circ} / 0^{\circ} / 30^{\circ} / 90^{\circ}\right)$, bending strength is more effective for the antisymmetrical sequence than for the symmetrical sequence, as shown in Fig. 15. For Kevlar/epoxy with H80, generally, the antisymmetrical sequence is more effective than the symmetrical sequence. Similar plots have been provided for buckling of structures with a delamination growth (propagation), in Fig 16-19. They have showed quite similar trends with the previous results, addressing no propagation. However, the magnitude of compressive loading while we have a delamination growth are significantly lower.
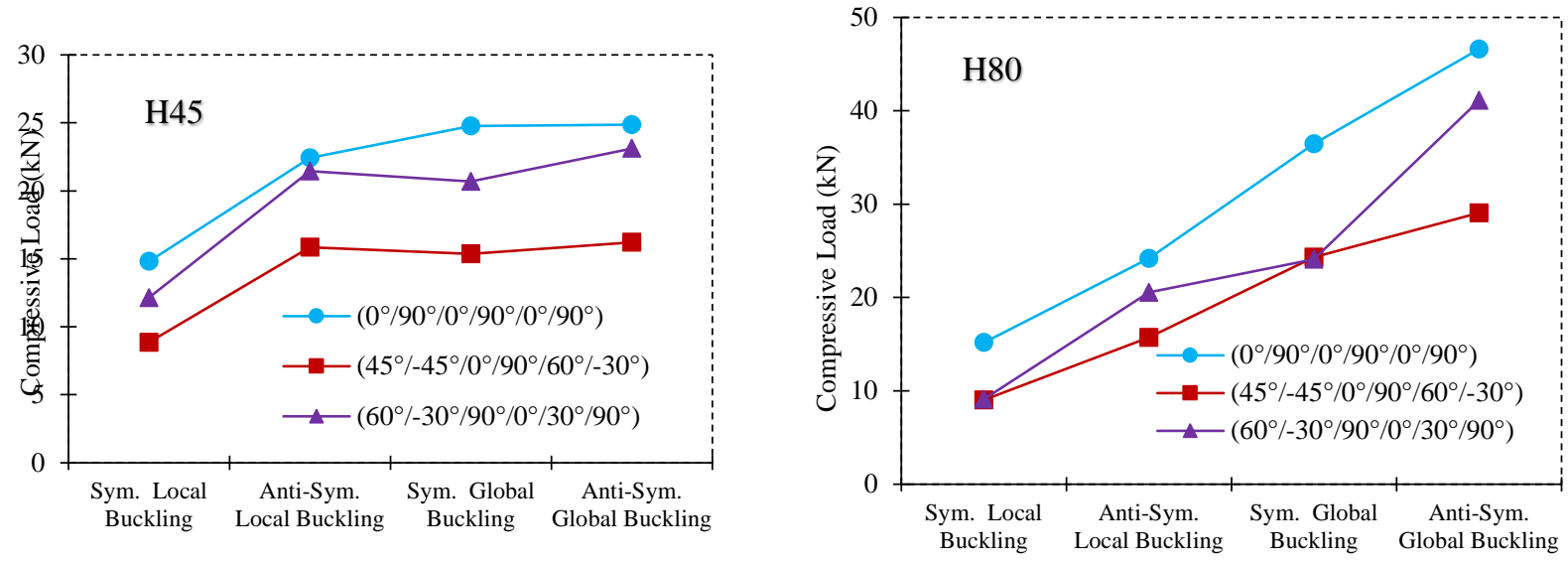

Figure 16. Compressive load of structure with delamination growth for H45, H80 cores and CFC/Epoxy shells 

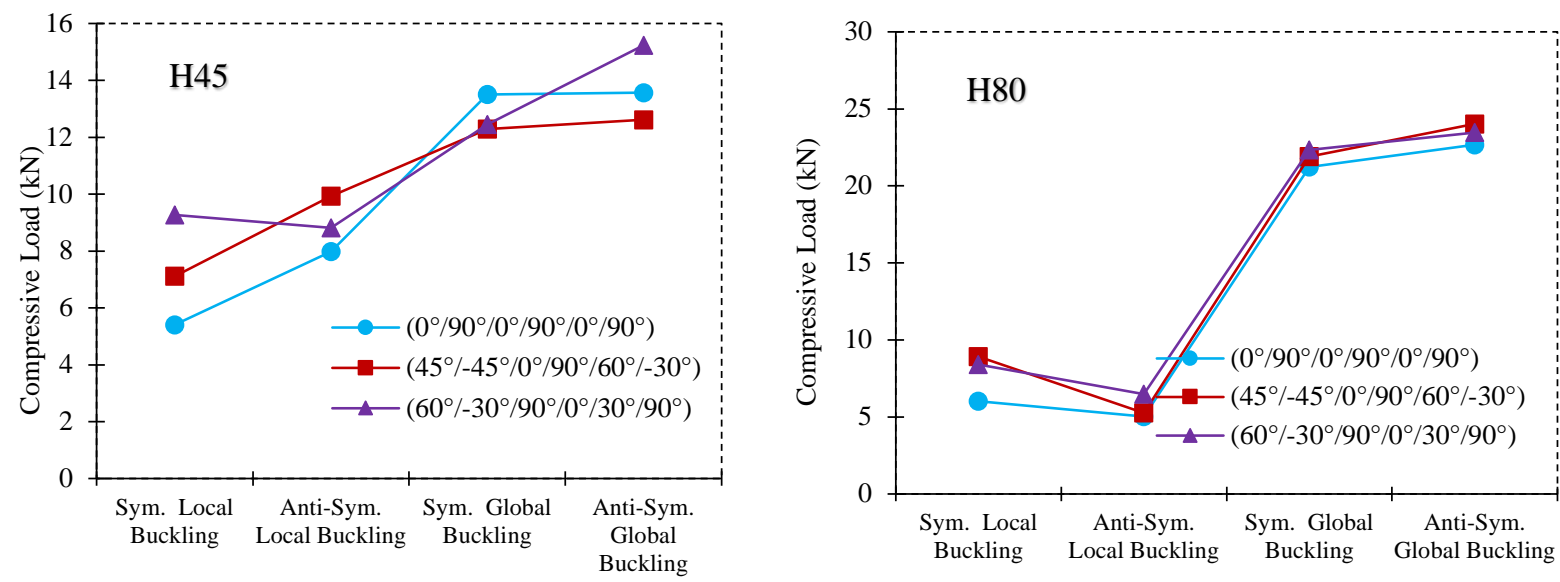

Figure 17. Compressive load of structure with delamination growth for H45, H80 cores and E-Glass/ Epoxy shell
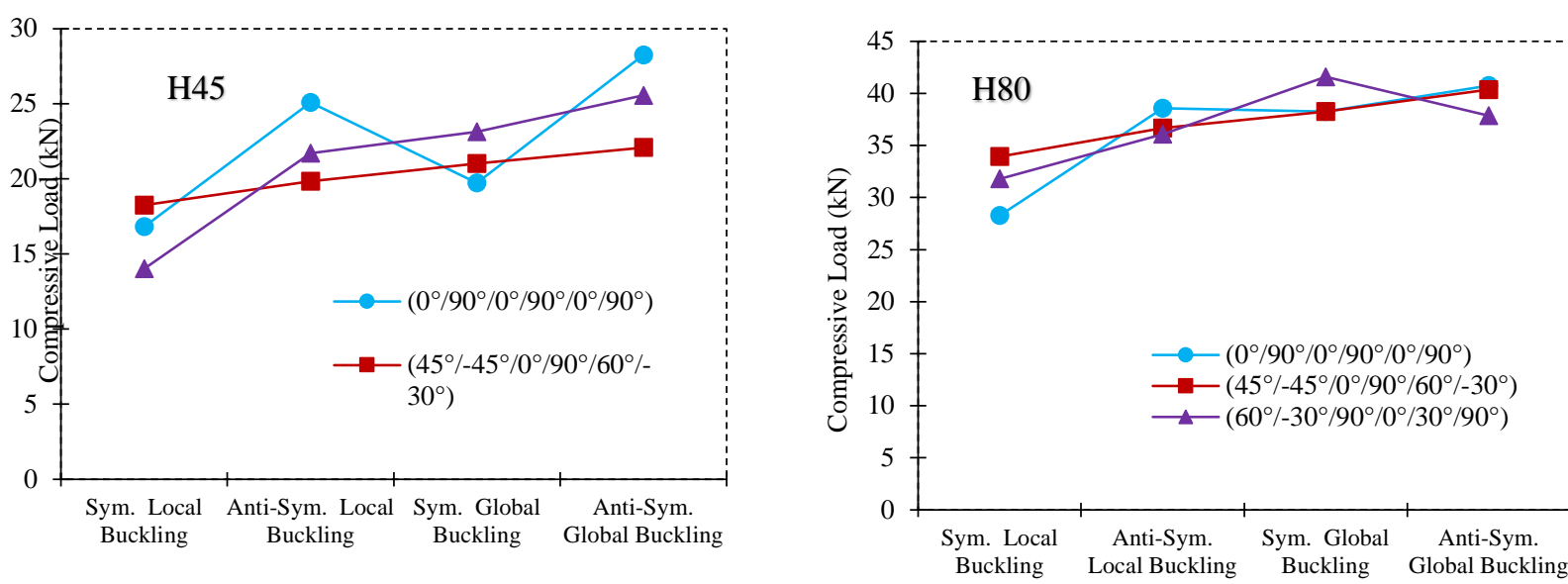

Figure 18. Compressive load of structure with delamination growth for H45, H80 cores and Kevlar/Epoxy shells

\section{NORMALIZED NUCKLING LOADS FOR STRUCTURE WITH MEBEDED DELAMINATION}

Value of applied load drop in structure with delamination and delamination growth in respect to perfect structure are given by means of bar diagrams in Fig 19-20. These figures are based on the results obtained from the numerical analysis in FEM simulations. These diagrams show that the normalized applied load decreases because of delamination and symmetrical and antisymmetrical sequences in layered composite shells. Furthermore, load dropped percent with respect to perfect sandwich are also provided in Table 5-6. 


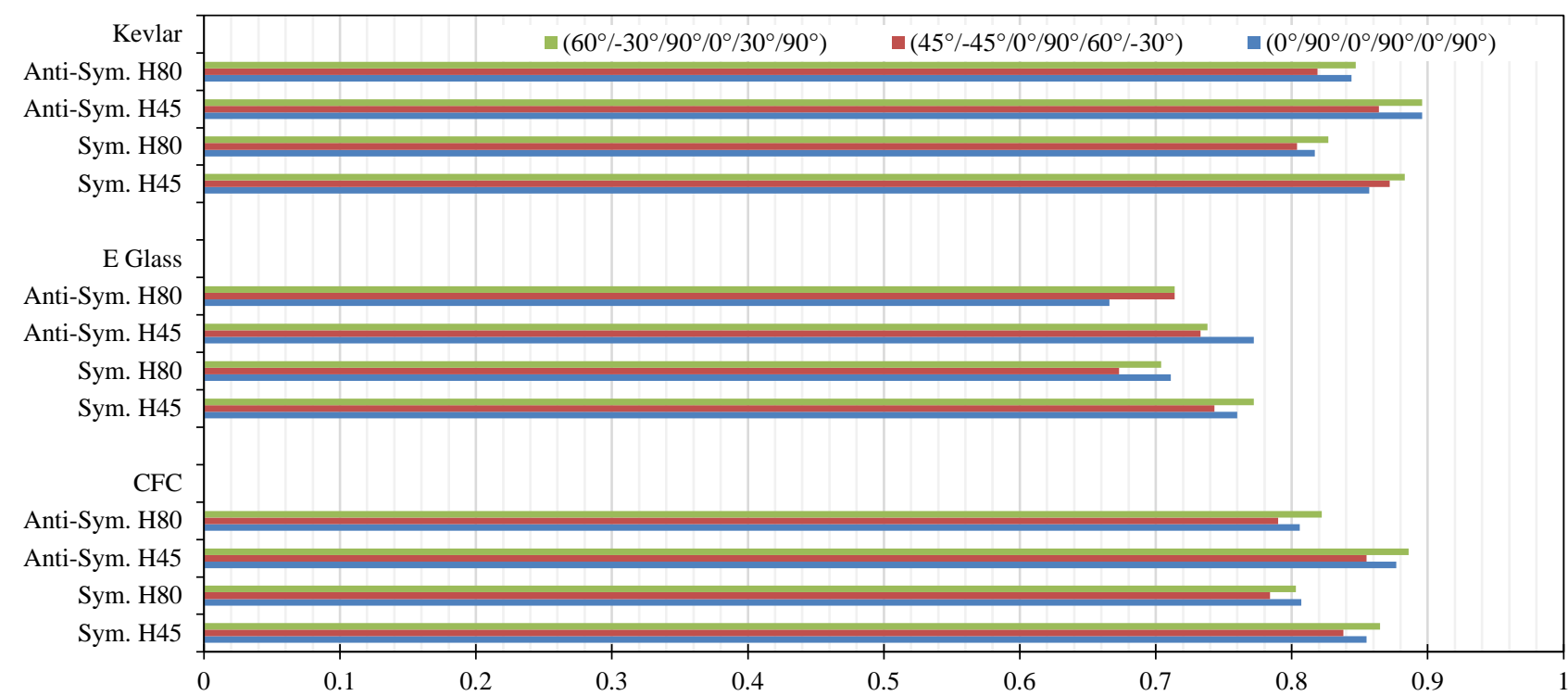

Figure 19. Normalized buckling loads for structure with delamination compare to perfect structure

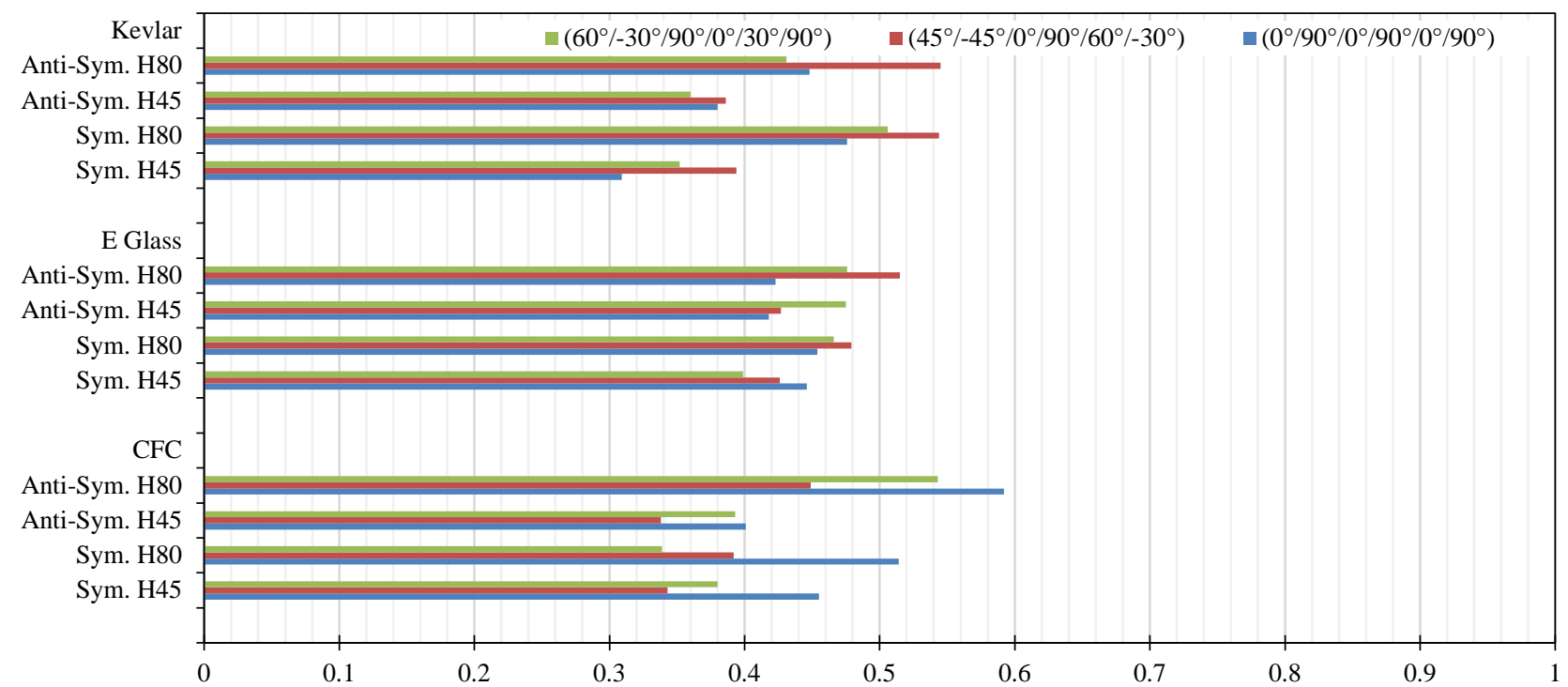

Figure 20. Normalized buckling loads for structure with delamination growth compare to perfect structure

Thus, the effects of symmetrical and antisymmetrical sequences differ in terms of structures according to the properties and material behavior, whereas for each of the layered composite shells, a particular sequence is better than the other sequence. In addition, the effect of symmetrical and antisymmetrical sequences in layered composite shells causes an increase in the bending strength of structures such that it can be used as an index for quality control and safety factor for the composite shells in specific industrial production processes of reinforced structures.

Table 5. Value of dropped load of structure with delamination vs. perfect structure

\begin{tabular}{|c|c|c|c|c|c|c|}
\hline \multirow{3}{*}{ Type } & \multicolumn{3}{|c|}{ Symmetrical Sequence } & \multicolumn{3}{|c|}{ Anti-symmetrical Sequence } \\
\hline & $\left(0^{\circ} / 90^{\circ} / 0^{\circ}\right)$ & $\left(45 \%-45^{\circ} / 0^{\circ} /\right.$ & $\left(60^{\circ} /-30^{\circ} / 90^{\circ} \%\right.$ & $\left(0^{\circ} / 90^{\circ} / 0^{\circ} /\right.$ & $\left(45^{\circ} /-45^{\circ} / 0^{\circ}\right.$ & $\left(60^{\circ} /-30^{\circ} / 90^{\circ} /\right.$ \\
\hline & $\left.90^{\circ} / 0^{\circ} / 90^{\circ}\right)$ & $\left.90 \% / 60^{\circ} /-30^{\circ}\right)$ & $\left.0^{\circ} / 30^{\circ} / 90^{\circ}\right)$ & $\left.90^{\circ} / 0^{\circ} / 90^{\circ}\right)$ & $\left.90^{\circ} / 60^{\circ} /-30^{\circ}\right)$ & $\left.0^{\circ} / 30^{\circ} / 90^{\circ}\right)$ \\
\hline CFC-H45 & $14.5 \%$ & $16.2 \%$ & $13.5 \%$ & $12.3 \%$ & $14.5 \%$ & $11.4 \%$ \\
\hline CFC-H80 & $19.3 \%$ & $21.6 \%$ & $19.7 \%$ & $19.4 \%$ & $21 \%$ & $17.8 \%$ \\
\hline $\begin{array}{l}\text { E-Glass- } \\
\text { H45 }\end{array}$ & $22.8 \%$ & $26.7 \%$ & $26.2 \%$ & $28.9 \%$ & $32.7 \%$ & $29.6 \%$ \\
\hline $\begin{array}{l}\text { E-Glass- } \\
\text { H80 }\end{array}$ & $28.9 \%$ & $32.7 \%$ & $29.6 \%$ & $33.4 \%$ & $28.6 \%$ & $28.6 \%$ \\
\hline
\end{tabular}




\begin{tabular}{llccccc}
$\begin{array}{l}\text { Kevlar- } \\
\text { H45 }\end{array}$ & $14.3 \%$ & $12.8 \%$ & $11.7 \%$ & $10.4 \%$ & $13.6 \%$ & $10.4 \%$ \\
\cline { 1 - 1 } $\begin{array}{l}\text { Kevlar- } \\
\text { H80 }\end{array}$ & $18.3 \%$ & $19.6 \%$ & $17.3 \%$ & $15.6 \%$ & $18.1 \%$ & $15.3 \%$ \\
\hline
\end{tabular}

Table 6. Value of dropped load of structure with delamination growth vs. perfect structure

\begin{tabular}{|c|c|c|c|c|c|c|}
\hline \multirow[b]{2}{*}{ Type } & \multicolumn{3}{|c|}{ Symmetrical Sequence } & \multicolumn{3}{|c|}{ Anti-symmetrical Sequence } \\
\hline & $\begin{array}{l}\left(0^{\circ} / 90^{\circ} / 0^{\circ} \%\right. \\
\left.90^{\circ} / 0^{\circ} / 90^{\circ}\right)\end{array}$ & $\begin{array}{l}\left(45^{\circ} /-45^{\circ} / 0^{\circ}\right) \\
\left.90^{\circ} / 60^{\circ} /-30^{\circ}\right)\end{array}$ & $\begin{array}{c}(60 \%- \\
30^{\circ} / 90^{\circ} \% \\
\left.0^{\circ} / 30^{\circ} / 90^{\circ}\right)\end{array}$ & $\begin{array}{l}\left(0^{\circ} / 90^{\circ} / 0^{\circ} /\right. \\
\left.90^{\circ} / 0^{\circ} / 90^{\circ}\right)\end{array}$ & $\begin{array}{l}\left(45^{\circ} /-45^{\circ} / 0^{\circ}\right. \\
\left.90^{\circ} / 60 \%-30^{\circ}\right)\end{array}$ & $\begin{array}{c}\left(60^{\circ} /-30^{\circ} / 90^{\circ}\right. \\
\left.0^{\circ} / 30^{\circ} / 90^{\circ}\right)\end{array}$ \\
\hline CFC-H45 & $54.5 \%$ & $65.7 \%$ & $62 \%$ & $59.9 \%$ & $66.2 \%$ & $60.7 \%$ \\
\hline CFC-H80 & $48.6 \%$ & $60.8 \%$ & $66.1 \%$ & $40.8 \%$ & $55.1 \%$ & $45.7 \%$ \\
\hline $\begin{array}{l}\text { E-Glass- } \\
\text { H45 } \\
\end{array}$ & $55.4 \%$ & $57.4 \%$ & $60.1 \%$ & $58.2 \%$ & $57.3 \%$ & $52.5 \%$ \\
\hline $\begin{array}{l}\text { E-Glass- } \\
\text { H80 }\end{array}$ & $54.6 \%$ & $52.1 \%$ & $53.4 \%$ & $57.7 \%$ & $48.5 \%$ & $52.4 \%$ \\
\hline $\begin{array}{l}\text { Kevlar- } \\
\text { H45 }\end{array}$ & $69.1 \%$ & $60.6 \%$ & $64.8 \%$ & $62 \%$ & $61.4 \%$ & $64 \%$ \\
\hline $\begin{array}{l}\text { Kevlar- } \\
\text { H80 }\end{array}$ & $52.4 \%$ & $45.6 \%$ & $49.4 \%$ & $55.2 \%$ & $45.5 \%$ & $56.9 \%$ \\
\hline
\end{tabular}

\section{CONCLUSION AND DISCUSSION}

Delamination is an important defect in the design and manufacturing of structures. Therefore, the effects of delamination, orientation, and symmetrical and asymmetrical sequences on the buckling behavior of reinforced structures with layered composite shells under axial loading are investigated. In this study, finite element analysis was performed to determine the bending strength of reinforcing layered composite shells. For more accurate simulations, the appropriate mesh size has been estimated as $5 \%$ of the core thickness.

The obtained results indicate that it is very important to consider the appropriate behavior of the material in the design of reinforced structures with layered composite shells in order to avoid delamination. The effects of symmetric and antisymmetric sequencing on the bucking stability of the structures is mainly attributed to the mechanical properties of the composite skin and the sandwich core. Delamination effects on reinforced structures are remarkable. With this in mind, delamination in reinforced structures causes dropping in the loads applied to the structure and reduces the bending strength of layered composite shells, leading rapidly to buckling and earlier failure. This study was performed based on the data obtained from the failure test of a reinforced structure with layered composite shells under axial loading by the finite element method. The interaction between the reinforcing layered composite shell and the core and the lack of tight connection of reinforcing layered composite shells to the core in the delamination area were studied through simulation and analysis during delamination modeling. For the study, layered fiber with epoxy matrix was used to consider the symmetrical and antisymmetrical sequences and orientation effect.

Further, 12-ply layered composite shells of identical thickness were made using Kevlar/epoxy, CFC/epoxy, and E-glass/epoxy.

Every sample indicates that the fiber orientation in the symmetrical and antisymmetrical sequences can be used as an index for quality control and as a safety factor for the layered composite shells in specific industrial production processes of reinforced structures.

The effects of delamination growth on compressive load were investigated by the cohesive elements. One of the main advantages of CZM is that delaminations are easily accounted for by simply removing the coupling between the elements representing the skins and those representing the core. Cohesive element method showed a very good meshing independency and they were also able 
to optimize the time of post processing. For each of the layered composite skin laminate, a particular sequence also exhibited the optimum compressive strength.

\section{REFERENCE}

[1] Y.B. Sudhir, P.R. Budarapu, N. Madhavi, Y. Krishna, Buckling analysis of thin wall stiffened composite panels. Computational Materials Science, Vol. 96, pp. 459-471, 2015.

[2] L.M. Kachanov, Delamination buckling of composite materials, pp. 5-7, Dordrcht: Kluwer Academic Publishers, 1988.

[3] B.F. Sørensen, K. Branner, E. Lund, J. Wedel-Heinen, J.H. Garm, Improved design of large wind turbine blade of fiber composites, Summary Report, Risø-R-1699 (EN), Risø National Laboratory for Sustainable Energy, Denmark, 2009.

[4] B.F. Sørensen, H. Toftegaard, S. Goutanos, K. Branner, P. Berring, E.Lund, Improved design of large wind turbine blade of fiber composites, Summary Report, Risø-R-1734 (EN), Risø National Laboratory for Sustainable Energy, Denmark, 2010.

[5] K. Branner, P. Berring, Compressive strength of thick composite panels, 32th International Symposium on Materials Science, Roskilde, Denmark, September 5-9, 2011.

[6] I.S.C. Benloulo, V. Sanchez-Galvez, A new analytical model to simulate impact onto ceramic/composite armors, International Journal of Impact Engineering, Vol. 21, pp. 461-471, 1998.

[7] M. Gaiotti, C.M. Rizzo, K. Branner, P. Berring, Finite elements modeling of delaminations in composite laminates, Advances in Marine Structures, Proceedings of the MARSTRUCT International Conference on Marine Structures, Hamburg, 28-30, Taylor and Francis Group, London, pp. 133-139, 2011.

[8] V. Vaddake, L.A. Carlsson, Experimental investigation of compression failure of sandwich specimens with face/core debond, Composites, Part B, Vol. 35, pp. 583- 590, 2004.

[9] Li, K., J. Wright, S. Modaresahmadi, D. Som, W. Williams, and J. Z. Bird. "Designing the first stage of a series connected multistage coaxial magnetic gearbox for a wind turbine demonstrator." In Energy Conversion Congress and Exposition (ECCE), 2017 IEEE, pp. 1247-1254. IEEE, 2017.

[10] H. Hocheng, C.C. Tsao, The path towards delamination-free drilling of composite materials, Journal of Materials Processing Technology, Vol. 167, pp. 251-264, 2005.

[11] J.E. Wright, Compound bifurcation in the buckling of a delaminated composite strut, Nonlinear Dynamics, Vol. 43, pp. 59-72, 2006.

[12] U.K. Mallela, A. Upadhyay, Buckling of laminated composite stiffened panels subjected to in-plane shear: A parametric study, Thin-Walled Structures, Vol. 44, pp. 354-361, 2006.

[13] T. Yoda, S.N. Atluri, Postbuckling analysis of stiffened laminated composite, Computational Mechanics, Vol. 9, pp. 390-404, 1992.

[14] C. Baley, P. Davies, Y. Grohens, G. Dolto, Application of interlaminar tests to marine composite, A Literature Review, Applied Composite Materials, Vol. 11 (2), pp. 99-126, 2003.

[15] Z. Aslan, M. Sahin, Buckling behavior and compressive failure of composite laminates containing multiple large delaminations. Composite Structures Vol. 89, pp. 382-390, 2009.

[16] D. Wang, M.M. Abdalla, Global and local buckling analysis of grid-stiffened composite panels. Composite Structures, Vol. 119, pp. 767-776, 2015.

[17] W. Ji, A.M. Waas, Accurate buckling load calculation of a thick orthotropic sandwich panel. Composites Science and Technology, Vol.72, pp. 1134-1139, 2012.

[18] S. Moradi, F. Taheri, Delamination buckling analysis of general laminated composite beams by differential quadrature method, Composites, Part B, Vol. 30, pp. 503-11, 1999.

[19] Fattahi, A. M., \& Safaei, B. (2017). Buckling analysis of CNT-reinforced beams with arbitrary boundary conditions. Microsystem Technologies, 1-13.

[20] Safaei, B., Fattahi, A.M. \& Chu, F. Microsyst Technol(2018) 24: 2663. https://doi.org/10.1007/s00542-017-3651-y

[21] H. Hosseini, S. Hosseini, B. Mohammadi, Delamination buckling growth in laminated composites using layerwiseinterface Element, Ocean Engineering, Vol. 92, pp. 1846-1856, 2010.

[22] P.F. Liu, J.Y. Zheng, On the through the width multiple delamination and buckling and postbuckling behavior of symmetric and unsymmetric composite laminates. Applied Composite Materials, 2013.

[23] S. Abrate, Impact on laminated composite materials, Applied Mechanical Review, Vol. 44, pp. 155-190, 1991.[24]

M.J. Pavier, M.P. Clarke, Experimental techniques for the investigation of the effects of impact damage on carbon/fiber composites, Composite Science Technology, Vol. 55, pp. 157-169, 1995.

[25] F.J. Plantema, The bending and buckling of sandwich beams- plates and shells, Sandwich Construction, John Wiley and Sons, New York, 1966. 
[26] M. Gaiotti, C.M. Rizzo, K. Branner, P. Berring, Finite elements modeling of delaminations in composite laminates, Advances in Marine Structures, Proceedings of the MARSTRUCT International Conference on Marine Structures, Hamburg, March 28-30, 2011.

[27] D. Chapelle, K.J. Bathe, The finite element analysis of shells- fundamentals, Springer-Verlag, Berlin, 2003.

[28] A.K. Kaw, Mechanics of Composite Materials, Second Edition, pp. 8-10, New York: CRC Press, Taylor and Francis Group, 2006.

[29] F.L. Matthews, G.A.O. Davies, D. Hitchings, C. Soutis, Finite Element Modelling of Composite Materials and Structures, pp. 3-5, Cambridge: Woodhead Publishing Ltd, 2000.

[30] M. Gaiotti, C. Rizzo, Finite element modeling strategies for sandwich composite laminated under compressive loading, Ocean Engineering, Vol. 63, pp. 44-51, 2013.

[31] F.L. Matthews, G.A.O. Davies, D. Hitchings, C. Soutis, Finite Element Modelling of Composite Materials and Structures, pp. 3-5, Cambridge: Woodhead Publishing Ltd, 2000.

[32] R.G. Wang, L. Zhang, J. Zhang, W.B. Liu, X.D. He, Numerical analysis of delamination buckling and growth in slender laminated composite using cohesive element method, Computational Materials Science 50, 20-3, 2010. 